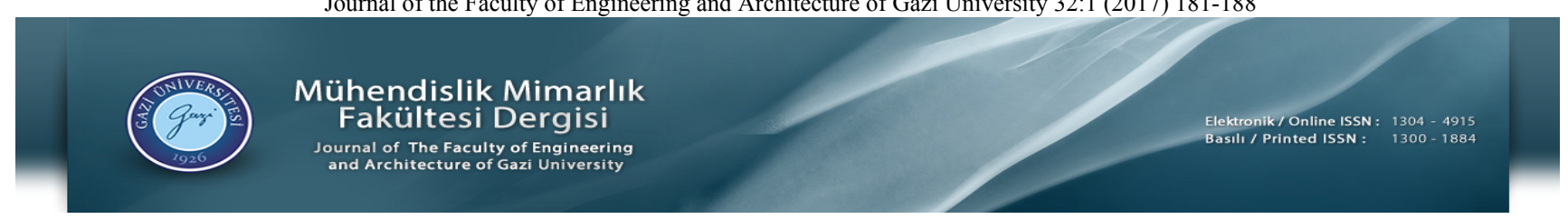

\title{
Kozmetik atık sularından fenton prosesiyle organik madde gideriminin ve kinetiğinin incelenmesi
}

Yalçın Kemal Bayhan ${ }^{1 *}$, Gökçe Didar Değermenci ${ }^{2}$

${ }^{1}$ Atatürk Üniversitesi, Mühendislik Fakültesi, Çevre Mühendisliği Bölümü, Erzurum, Türkiye

${ }^{2}$ Kastamonu Üniversitesi, Mühendislik ve Mimarlık Fakültesi, Çevre Mühendisliği Bölümü, Kastamonu, Türkiye

\section{Ö N E Ç I K A N L A R}

- Maksimum KOİ giderimi için optimum parametreler belirlendi

- Fenton prosesi ile KOİ'nin \%89,6's1 ve TOK'un \%76,9'u giderildi

- Yalancı birinci derece kinetik modeli atık su arıtımını iyi tanımlamaktadır

Makale Bilgileri

Geliş: 30.12 .2015

Kabul: 02.04.2016

DOI:

10.17341/gazimmfd.300609

Anahtar Kelimeler:

Kozmetik atık suyu,

fenton prosesi,

oksidasyon,

kinetik

\section{ÖZET}

Kozmetik endüstrisi atık suların arıtımı için fenton prosesinin uygulanabilirliği araştırılmıştır. Proses süresince KOİ ve TOK giderimi üzerine reaksiyon süresi, $\mathrm{pH}$, sıcaklık, $\mathrm{Fe}^{+2}$ ve $\mathrm{H}_{2} \mathrm{O}_{2}$ konsantrasyonlarının etkileri karakterize edilmiştir. Elde edilen sonuçlara göre, $36^{\circ} \mathrm{C}$ 'de optimum reaksiyon süresi, $\mathrm{pH}, \mathrm{Fe}^{+2}$ ve

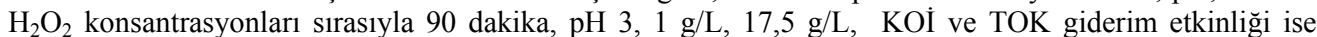
$\% 89,6$ ve \%76,9 olarak belirlenmiştir. Ayrıca, farklı sıcaklık değerleri araştırılarak prosesin kinetik analizi gerçekleştirilmiştir. Prosesin yalancı birinci dereceden reaksiyon kinetiğine uyduğu ve aktivasyon enerjisinin $\left(E_{a}\right) 117,7 \mathrm{~kJ} / \mathrm{mol}$ olduğu belirlenmiştir.

\section{Investigation ff kinetic and removal of organic matter from cosmetic wastewaters by fenton process}

\section{H I G H L I G H T S}

- $\quad$ Optimum parameters were determined for maximum COD efficiency

- Fenton process removed $89.6 \%$ of COD and $76.9 \%$ of TOC

- The pseudo-first order kinetic model well describes wastewater treatment

Article Info

Received: 30.12 .2015

Accepted: 02.04.2016

DOI:

10.17341/gazimmfd.300609

Keywords:

Cosmetic wastewater, fenton process, oxidation,

kinetics

\begin{abstract}
The application of the Fenton process for the treatment of cosmetics industry wastewater was investigated. The effects of different parameters such as reaction time, $\mathrm{pH}$, temperature, $\mathrm{Fe}^{2+}$ and $\mathrm{H}_{2} \mathrm{O}_{2}$ concentrations on COD and TOC removal during the process were characterized. According to the obtained results in $36^{\circ} \mathrm{C}$ temperature, the optimum reaction time, $\mathrm{pH}, \mathrm{Fe}^{2+}$ and $\mathrm{H}_{2} \mathrm{O}_{2}$ concentrations were 90 minutes, $\mathrm{pH} \mathrm{3,1}$ $\mathrm{g} / \mathrm{L}$ and $17.5 \mathrm{~g} / \mathrm{L}$, respectively. COD and TOC removal efficiencies were $89.6 \%$ and $76.9 \%$. Furthermore, the COD and TOC removal via the Fenton process at different temperatures were investigated and kinetic analysis was performed based on COD. The COD degradation during the Fenton process followed pseudo first-order reaction kinetics. The apparent activation energy $\left(E_{a}\right)$ was $117.7 \mathrm{~kJ} / \mathrm{mol}$.
\end{abstract}

\footnotetext{
*Sorumlu Yazar/Corresponding author: ybayhan@atauni.edu.tr / Tel: +90 5323174694
} 


\section{GİRİŞ (INTRODUCTION)}

Günümüzde artan nüfusun ihtiyacı ve tüketimi doğrultusunda endüstriler gelişmekte ve bu artan talep ile beraber mevcut olan sanayi tesislerine birçoğu daha eklenmektedir. Sanayi dallarına bağlı olarak kirlilik parametreleri de değișiklik göstermekte olup farklı karakterde atık sular oluşmaktadır. Bu sanayi dallarından kozmetik ürünlerine olan ilginin artmasıyla bitkisel şampuan, saç kremi, saç boyası, tüy dökücü krem, güneş kremleri ve nemlendiriciler gibi geniş üretim yelpazesine sahip kozmetik ürünlerden kaynaklanan atık sular açığa çıkmaktadır.

Kozmetik atık suyu organik ve inorganik çeşitli bileşikleri içerir. Organik bileşikler başlıca; hidrokarbonlar, proteinler, eterler, esterler, aldehitler, ketonlar, alkoller, karboksilik asitler ve daha karmaşık türevleri ihtiva eder. İnorganikler ise; asitler, hidroksitler, tuzlar, oksitler ve ağır metal bileşikleridir [1]. Kozmetik atık suyunun karakterizasyonu, üretilen ürün profilinin değişken olması nedeniyle atık suyun kirlilik yükü ve bileşimine bağlı olarak değişmektedir [2]. Kozmetik atık suları, içerdiği toksik kirleticiler nedeniyle arıtımı oldukça zor bir atık sudur. Bu atık suların arıtılmadan alıcı ortamlara birakılmaları ciddi çevre problemlerine neden olmaktadır. Kozmetik atık suları nispeten yüksek olan kimyasal oksijen ihtiyacı (KOİ), askıda katı madde (AKM), yağlar ve deterjanlardan oluşan kompleks bir atık sudur [3]. Kozmetik atık sularının arıtımı kimyasal, biyolojik ve ileri arıtım yöntemleri veya bunların kombinasyonları ile gerçekleştirilebilir. Literatürde kozmetik atık suyun giderimi için; koagülasyon [2], Fenton prosesi [4], elektro-koagülasyon [5], katalitik 1slak peroksit oksidasyonu [6], ultrafiltrasyon [7], anaerobik aritım [3], ardış1k kesikli reaktörde ve membran biyoreaktörde aerobik arıtım [8, 9] gibi metotlar uygulanmıştır. Kozmetik atık suları biyolojik olarak kolay parçalanamayan bileşiklerden oluştuğu için klasik biyolojik arıtım prosesleri ile arıtılmaları oldukça zordur.

Son zamanlarda biyolojik olarak zor parçalanan atık suları daha zararsız forma (örn: karbondioksit, su ve inorganik tuzlar) oksitleyerek atık suların arıtımında çevre dostu olarak bilinen ileri arıtma yöntemleri kullanılmaktadır. Fenton prosesi bu yöntemlerden biridir [10, 11]. Fenton reaksiyonunda; demir ve demir tuzları ile hidrojen peroksitin katalitik parçalanması aşamalarında oluşan bir dizi reaksiyon sonrasında hidroksil radikali ( $\mathrm{OH})$ oluştuğunu ortaya konmuştur [12]. Bu proses, homojen katalitik oksidasyon prosesi olarak asidik şartlarda hidroksil radikali ( $\mathrm{OH})$ oluşumu esasına dayanmaktadır (R1, R2). Fenton oksidasyon prosesi basamakları aşağıdaki gibidir $[13,14]$.

$$
\begin{aligned}
& \mathrm{Fe}_{(a q)}^{2+}+\mathrm{H}_{2} \mathrm{O}_{2} \rightarrow \mathrm{Fe}_{(a q)}^{3+}+\mathrm{OH}_{(a q)}^{-}+{ }^{\circ} \mathrm{OH} \\
& \mathrm{Fe}_{(a q)}^{3+}+\mathrm{H}_{2} \mathrm{O}_{2} \rightarrow \mathrm{Fe}_{(a q)}^{2+}+\mathrm{H}_{(a q)}^{+}+\mathrm{HO}_{2}^{\bullet}
\end{aligned}
$$

Genel olarak bakıldığında Fenton prosesi dört basamaktan oluşmaktadır. Bunlar; pH ayarlama, oksidasyon reaksiyonu, nötralizasyon ve koagülasyon ile çöktürme reaksiyonudur. $\mathrm{Bu}$ şekilde organik maddeler oksidasyon ve koagülasyon olmak üzere iki aşamada giderilmektedir [15]. Literatürde yapılan çalışmalara göre Fenton prosesi; organik maddelerin giderilmesinde [16], toksisitenin azaltılmasında [17], biyolojik arıtıma verilmeden önce ön arıtım olarak [18] ve renk gideriminde [19] yaygın olarak kullanılmaktadır. Bu çalışmanın amacı kozmetik atık suyunun aritımında Fenton oksidasyonu ile organik madde giderim performansını etkileyen parametrelerin (reaksiyon süresi, $\mathrm{pH}, \mathrm{Fe}^{2+}$ dozaj1, $\mathrm{H}_{2} \mathrm{O}_{2}$ dozaj1 ve sicaklık) araştırılması ve KOİ'ye dayalı kinetik parametrelerin belirlenmesidir.

\section{DENEYSEL METOD (EXPERIMENTAL METHOD)}

\subsection{Malzemeler(Materials)}

Atık su örnekleri İstanbul' da bulunan bitkisel şampuan, saç kremi, saç boyası, tüy dökücü krem ve güneş kremi üreten bir kozmetik fabrikasından temin edilmiştir. Tablo 1'de bu atık suyun karakterizasyonuna ait bazı özellikler ve İstanbul $\mathrm{Su}$ ve Kanalizasyon İdaresi (İSKİ) tarafindan atık suların kanalizasyona deşarj yönetmeliğinde belirtilen deşarj limitleri verilmiştir [20]. Deneyler sırasında kullanılan kimyasallar analitik saflıkta olup Merck firmasından temin edilmiştir.

Tablo 1. Kozmetik atık suyunun fiziko-kimyasal karakterizasyonu ve deşarj limitleri (Physico-chemical characterization of cosmetic wastewater and discharge limit values)

\begin{tabular}{lll}
\hline Parametreler & Değerler & Deşarj limitleri \\
\hline $\mathrm{pH}$ & $4,52 \pm 0,34$ & $6-12$ \\
İletkenlik $(\mu \mathrm{S} / \mathrm{cm})$ & $1124 \pm 172$ & - \\
TKOİ $(\mathrm{mg} / \mathrm{L})$ & $7940 \pm 343$ & 1000 \\
ÇKOİ $(\mathrm{mg} / \mathrm{L})$ & $7076 \pm 127$ & - \\
TOK $(\mathrm{mg} / \mathrm{L})$ & $2041 \pm 85$ & - \\
BOİ $_{5}(\mathrm{mg} / \mathrm{L})$ & $4572 \pm 262$ & - \\
AKM $(\mathrm{mg} / \mathrm{L})^{1900 \pm 88}$ & 500 \\
\hline
\end{tabular}

\subsection{Deneysel Sistem (Experimental System)}

Fenton oksidasyonu ile ilgili deneysel çalışmalar $500 \mathrm{~mL}$ hacminde boro silikat ceketli reaktörde $250 \mathrm{~mL}$ kozmetik atık suyu numunesi kullanılarak gerçekleştirilmiştir. Sicaklık Julabo (F25-ME) marka cihaz ile kontrol edilmiştir. Reaksiyon süresince (180 dakika) karıştırma işlemi Heidolph (MR 3003) marka manyetik karıştırıcı kullanılarak sağlanmıştır. Fenton prosesi deneylerinde seyreltik $\mathrm{H}_{2} \mathrm{SO}_{4}$ ve $\mathrm{NaOH}$ ilave edilerek $\mathrm{pH}$ ayarlamas1 yapılmıştır. Sırasıyla $\mathrm{FeSO}_{4} \cdot 7 \mathrm{H}_{2} \mathrm{O}$ ve $\mathrm{H}_{2} \mathrm{O}_{2}$ ilavesinden sonra ceketli reaktörde 150 rpm'de 180 dakika karıştırma uygulanmıştır. Önceden belirlenen zamanlarda reaktörden 
alınan numunelerin pH'sı sodyum hidroksit ile 7-8 aralığına ayarlanarak çökelmesi sağlanmıştır. Daha sonra katı sıvı ayrımı için numuneler $6000 \mathrm{rpm}$ de 5 dakika Hettich (EBA 20) cihazı kullanılarak santrifüjlenmiştir. Üst fazdan alınan numunelerde $\mathrm{KOI}, \mathrm{H}_{2} \mathrm{O}_{2}$ ve toplam organik karbon (TOK) analizleri yapılmıştır.

\subsection{Analiz Yöntemleri (Analytical Procedures)}

Hidrojen peroksit konsantrasyonu spektrofotometrik (WTW-Spectroflex 6600) olarak 352 nm de [21] ölçülmüş, KOİ (spektrofotometrik metotla) APHA standart metotlara göre analiz edilmiş [22], Hidrojen peroksit'in KOI'ye yaptığı girişimi düzeltmek amacıyla Talinli ve Anderson tarafından geliştirilen denklem kullanılmıştır [23]. TOK konsantrasyonu ise Teledyne-Tekmar 9000 kullanılarak belirlenmiştir.

\section{SONUÇLAR VE TARTIŞMALAR (RESULTS AND DISCUSSIONS)}

Fenton prosesinde KOİ ve TOK giderimi üzerine reaksiyon süresi, pH, sicaklık, $\mathrm{Fe}^{+2}$ ve $\mathrm{H}_{2} \mathrm{O}_{2}$ konsantrasyonlarının etkileri aşağıda verilmiştir.

\subsection{Reaksiyon Süresinin Etkisi (The effect of Reaction Time)}

Reaksiyon süresinin, atık sulardaki kirlilik yükü ve organik maddenin türüne bağlı olarak değişebildiği bilinmektedir. Yüksek organik yük içeren atık sularda başlangıçtaki $\mathrm{Fe}^{2+}$ ve $\mathrm{H}_{2} \mathrm{O}_{2}$ konsantrasyonunu yüksek tutmak reaksiyon performansı açısından fayda sağlamaktadır. KOİ ve TOK giderimi üzerine reaksiyon süresinin etkisinin belirlenmesi amaciyla $\mathrm{pH} 3$ 'de, 17,5 g/L $\mathrm{H}_{2} \mathrm{O}_{2}, 2 \mathrm{~g} / \mathrm{L} \mathrm{Fe}^{2+}$ ilavesiyle $23^{\circ} \mathrm{C}$ 'de 240 dakika boyunca belirli aralıklarla numuneler alınarak KOİ ve TOK analizleri yapılmış ve elde edilen sonuçlar Şekil 1'de verilmiştir.

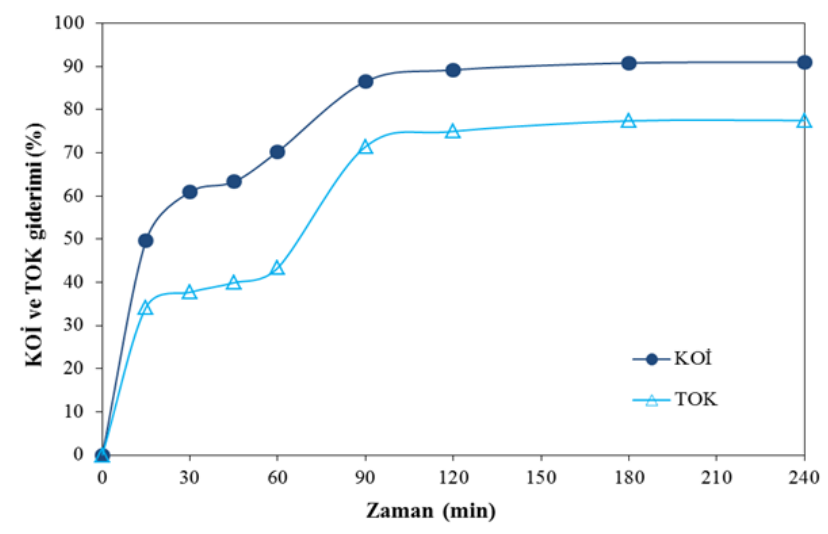

Şekil 1. KOİ ve TOK giderim verimleri üzerine reaksiyon süresinin etkisi $\left(\mathrm{pH}=3, \mathrm{~T}=23^{\circ} \mathrm{C}, \mathrm{H}_{2} \mathrm{O}_{2}=17,5 \mathrm{~g} / \mathrm{L}, \mathrm{Fe}^{2+}=2\right.$ $\mathrm{g} / \mathrm{L}, \mathrm{KOI}=7826 \mathrm{mg} / \mathrm{L}, \mathrm{TOK}=2041 \mathrm{mg} / \mathrm{L}$ )

(Effect of reaction time on COD and TOC removal efficiencies)

Şekil 1 incelendiğinde KOİ giderimleri 90'ıncı dakikaya kadar sürekli olarak artmış ve \%86,5'e ulaşmıştır. 240 dakika sonunda ise KOİ giderimi \%91 olarak bulunmuştur.
90 ile 240'1ncı dakikalar arasında KOİ gideriminde az bir artış gözlemlenmiş olup kullanılan $\mathrm{H}_{2} \mathrm{O}_{2}$ ve $\mathrm{Fe}^{2+}$ miktarları göz önüne alındığında 90 dakikalık bir reaksiyon süresinin ekonomiklik ve zaman tasarrufu açısından yeterli olacağ1 görülmektedir. $\mathrm{Bu}$ süreden sonra KOİ değerleri 1055 mg/L'den 240 dakika sonunda $704 \mathrm{mg} / \mathrm{L}$ 'ye düşmüştür. TOK değerleri KOİ değerleri ile paralellik göstermekte olup 90'incı dakikaya kadar artarak \%71,5'e ulaşmıştır. 90 ile 240'ıncı dakikalar arasında TOK gideriminde de pek fazla bir değişim olmamıştır. KOİ ve TOK giderimleri incelendiğinde 90 dakika sonunda organik maddenin büyük bir kısmının giderildiği görülmektedir. Diğer taraftan ilave edilen $\mathrm{H}_{2} \mathrm{O}_{2}$ ve $\mathrm{Fe}^{2+}$ konsantrasyonlarının etkisine ait sonuçlardan, konsantrasyonun azalmasıyla ortamda üretilen ${ }^{\circ} \mathrm{OH}$ radikallerinin azalmasından dolayı reaksiyonun yavaşladığı görülmüş ve bu nedenle çalışma şartlarında en uygun reaksiyon süresi olarak 180 dakika seçilmiştir. Kozmetik atık suyunun Fenton prosesiyle arıtıldığ 1 bir çalışmada benzer bulgulara ulaşılmıştır [4].

\section{2. $p H^{\prime}$ 'n etkisi (The Effect of $p H$ )}

Optimum $\mathrm{pH}$ değerinin belirlenmesi amaciyla $\mathrm{pH}$ 2-7 aralığında sabit sıcaklık, $\mathrm{Fe}^{2+}$ ve $\mathrm{H}_{2} \mathrm{O}_{2}$ konsantrasyonlarında Fenton prosesi uygulanmış olup elde edilen sonuçlar Şekil 2'de verilmiştir. Şekil 2 incelendiğinde $\mathrm{pH} 7$ değerinde KOİ giderim verimi $\% 82,8$ iken atık suyun kendi $\mathrm{pH}$ değeri olan 4,22 ‘de KOİ giderim verimi ise $\% 85,4$ olarak bulunmuştur.

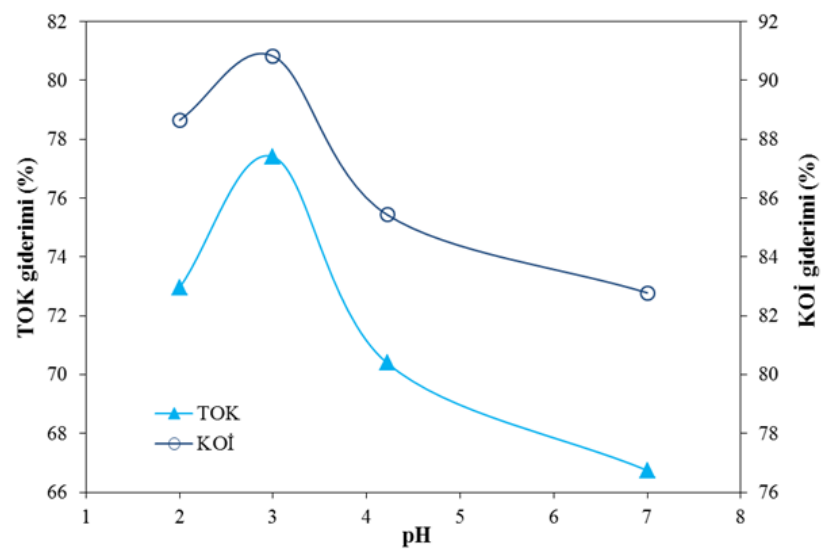

Şekil 2. Başlangıç pH değerinin KOİ ve TOK giderim verimlerine etkisi (Reaksiyon süresi $=180$ dakika, $\mathrm{T}=23^{\circ} \mathrm{C}$, $\mathrm{H}_{2} \mathrm{O}_{2}=17,5 \mathrm{~g} / \mathrm{L}, \mathrm{Fe}^{2+}=2 \mathrm{~g} / \mathrm{L}, \mathrm{KOI}=7826 \mathrm{mg} / \mathrm{L}, \mathrm{TOK}=2041$ $\mathrm{mg} / \mathrm{L}$ ) (The effect of initial $\mathrm{pH}$ on COD and TOC removal efficiencies)

En yüksek KOİ giderim verimi ise $\mathrm{pH} 3$ 'te elde edilmiş olup \%90,8 olarak hesaplanmıştır. pH 2 değerinde ise KOİ giderim verimi azalarak $\% 88,7$ 'ye azalmıştır. TOK giderim verimlerine bakıldığında ise en yüksek giderim verimi $\% 77,4$ ile yine $\mathrm{pH} 3$ 'te olduğu görülmektedir. Fenton oksidasyon prosesinde en önemli parametre $\mathrm{pH}$ olup, bu değer 2,5 - 4 gibi dar bir aralıkta değişmektedir. Bu aralığın dişındaki $\mathrm{pH}$ değerlerinde daha az ${ }^{\circ} \mathrm{OH}$ radikali üretildiğinden oksidasyon azalmaktadır. Optimum $\mathrm{pH}$ değer aralığının üzerinde alkalinite tarafından $\mathrm{H}_{2} \mathrm{O}_{2}$ 'nin ayrışması, oluşan demir hidroksit komplekslerinin formasyonu ve ${ }^{\circ} \mathrm{OH}$ 
radikallerinin süpürülmesi oksidasyon yeteneğini düşürdüğünden yüksek miktarda ${ }^{\circ} \mathrm{OH}$ radikali üretmek ve organik bileşikleri okside etmek için başlangıç $\mathrm{pH}$ değerinin asidik aralık da (3-4) olması zorunlu bir durum gibi düşünülmektedir. Benzer açıklamalara incelenen araştırmalarda da rastlanmıştır [24, 25]. Elde edilen bulgular neticesinde etkin giderim verimlerinin $\mathrm{pH} 3$ 'te gerçekleştiği belirlenmiş olup, yapılan benzer araştırma sonuçlarıyla da uygunluğu görülmüştür [26, 27].

\section{3. $\mathrm{H}_{2} \mathrm{O}_{2}$ Dozajinın Etkisi (The Effect of $\mathrm{H}_{2} \mathrm{O}_{2}$ Dosage)}

Bilindiği gibi $\mathrm{H}_{2} \mathrm{O}_{2},{ }^{\circ} \mathrm{OH}$ radikali kaynağıdır. $\mathrm{H}_{2} \mathrm{O}_{2}$ miktarı Fenton prosesinin tamamında rol oynamaktadır [15]. Fenton prosesinde en uygun $\mathrm{H}_{2} \mathrm{O}_{2}$ miktarının belirlenmesi amaciyla farkl $\mathrm{H}_{2} \mathrm{O}_{2}$ konsantrasyonlarında $\mathrm{pH}, \mathrm{Fe}^{2+}$ konsantrasyonu ve sicaklik sabit tutularak denemeler yapılmıştır. $\mathrm{Fe}^{2+}$ konsantrasyonu $2 \mathrm{~g} / \mathrm{L}$, pH 3 ve sicaklık $23^{\circ} \mathrm{C}$ 'de sabit tutularak $\mathrm{H}_{2} \mathrm{O}_{2}$ konsantrasyonları sirasiyla 4,37 g/L, 8,75 g/L, 17,5 g/L ve 23,8 g/L olacak şekilde dozlamalar yapılmıştır. Elde edilen sonuçlar Şekil 3'te verilmiştir.
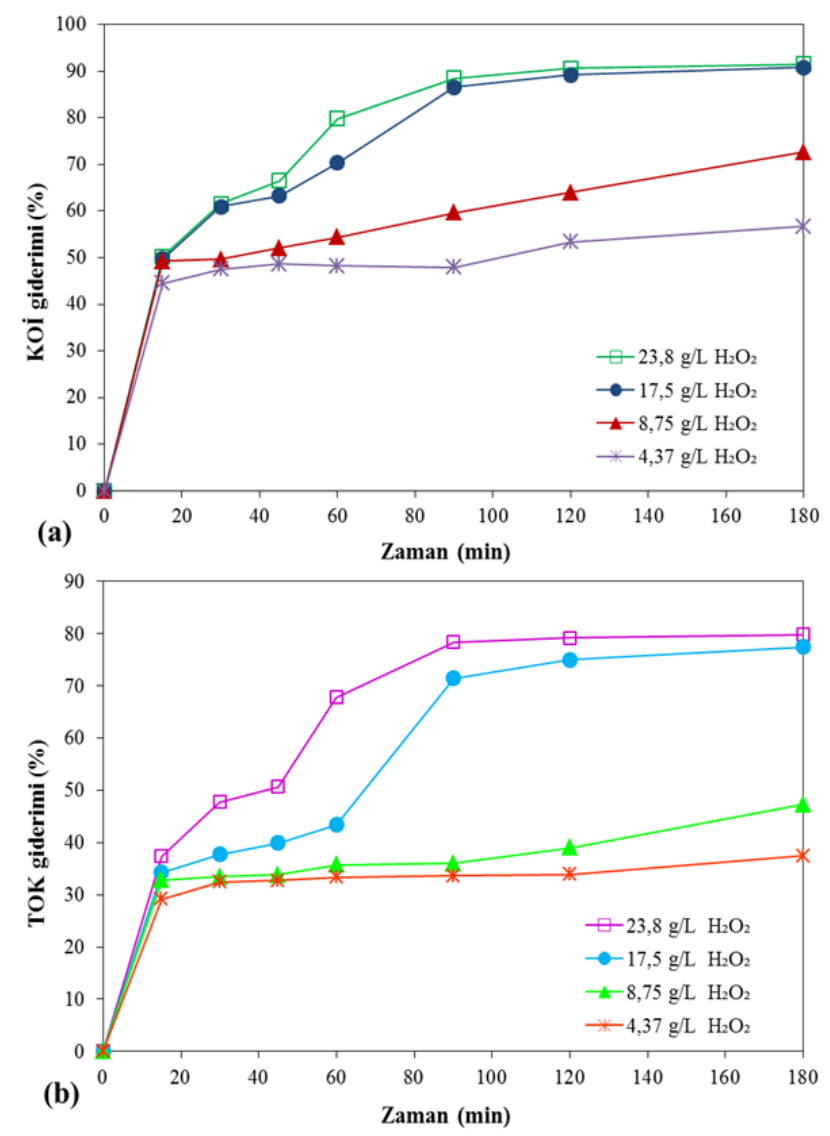

Şekil 3. Farklı $\mathrm{H}_{2} \mathrm{O}_{2}$ dozajının KOİ (a) ve TOK (b) giderim verimlerine etkisi $(\mathrm{KOI}=7826 \mathrm{mg} / \mathrm{L}, \mathrm{TOK}=2041 \mathrm{mg} / \mathrm{L}$, $\mathrm{pH}=3, \mathrm{Fe}^{2+}=2 \mathrm{~g} / \mathrm{L}, \mathrm{T}=23^{\circ} \mathrm{C}$ ) (Effect of different $\mathrm{H}_{2} \mathrm{O}_{2}$ concentrations on (a) COD (b) TOC removal efficiencies)

$\mathrm{H}_{2} \mathrm{O}_{2}$ konsantrasyonu 4,37 g/L'de KOİ giderim verimi 180'inci dakikada \%56,7 olarak bulunmuştur. $\mathrm{H}_{2} \mathrm{O}_{2}$ konsantrasyonunun $8,75 \mathrm{~g} / \mathrm{L}$ 'ye çıkarılması ile KOİ giderim verimi artarak 180'inci dakikada \%72,7 olarak bulunmuştur. $\mathrm{H}_{2} \mathrm{O}_{2}$ konsantrasyonu sırasıyla 17,5 ve 23,8 g/L'ye çıkarılması ile KOİ giderim verimleri 180'inci dakikada sırasıyla \%90,8 ve \%91,5 olarak bulunmuştur. $\mathrm{H}_{2} \mathrm{O}_{2}$ konsantrasyonunun 23,8 g/L'ye çıkarılması KOİ giderimini çok az etkilemiş olup optimum $\mathrm{H}_{2} \mathrm{O}_{2}$ konsantrasyonu olarak 17,5 g/L belirlenmiştir (Şekil 3a). $\mathrm{H}_{2} \mathrm{O}_{2}$ konsantrasyonuna bağlı olarak TOK giderimleri Şekil $3 \mathrm{~b}$ 'de verilmektedir. TOK giderimleri incelendiğinde artan $\mathrm{H}_{2} \mathrm{O}_{2}$ konsantrasyonu ile 180 dakika sonunda ise $\% 37,5$, $\% 47,3, \% 77,4$ ve $\% 79,8$ giderim sağlanmıştır. $\mathrm{H}_{2} \mathrm{O}_{2}$ konsantrasyonu 17,5 ve $23,8 \mathrm{~g} / \mathrm{L}$ 'de 180 dakika sonunda TOK konsantrasyonları sirasiyla 461 ve $412 \mathrm{mg} / \mathrm{L}$ 'dir. Literatürde Fenton oksidasyonunda atık suların ihtiyaç duyduğu $\mathrm{H}_{2} \mathrm{O}_{2}$ miktarı ile KOİ arasındaki oran 2,12 olarak verilmiştir [4].

Yapılan dozlamalar sonucunda $\mathrm{H}_{2} \mathrm{O}_{2} / \mathrm{KOI}$ oranı sirasiyla $0,56,1,12,2,24$ ve 3,04 olarak hesaplanmış olup $\mathrm{H}_{2} \mathrm{O}_{2} / \mathrm{KOI}$ oranına bağlı olarak 180 dakika sonunda KOİ giderimleri Şekil 4'te verilmiştir. $\mathrm{H}_{2} \mathrm{O}_{2} / \mathrm{KOI}$ oranına bağlı olarak KOİ giderim verimleri \%56,7 ile \%91,5 arasında değişmektedir. Optimum $\mathrm{H}_{2} \mathrm{O}_{2}$ konsantrasyonunda ise $\mathrm{H}_{2} \mathrm{O}_{2}$ /KOİ oran1 2,24 olarak hesaplanmış olup literatürde verilen 2,12 değerine çok yakındır. $\mathrm{H}_{2} \mathrm{O}_{2} / \mathrm{KOİ}$ oranının artması ile KOİ gideriminde $\mathrm{ki}$ artış ${ }^{\circ} \mathrm{OH}$ radikallerinin üretiminden kaynaklanmaktadır.

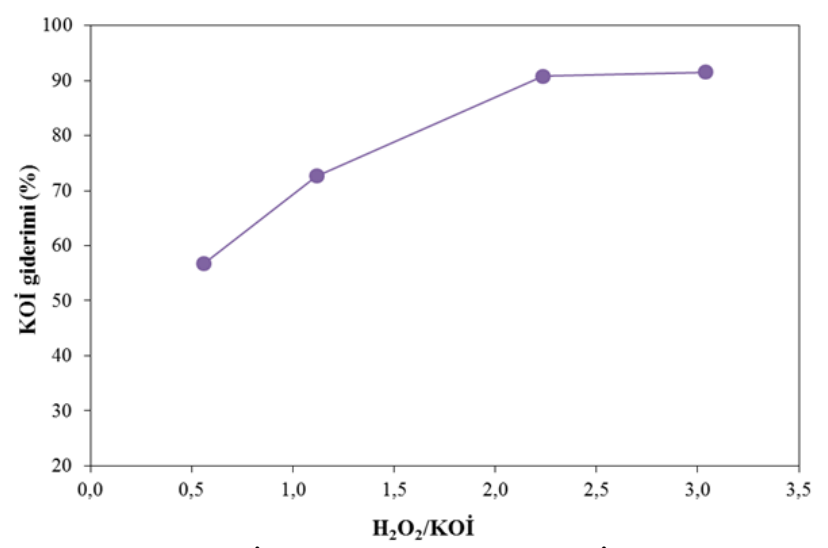

Şekil 4. $\mathrm{H}_{2} \mathrm{O}_{2}$ /KOİ oranına bağlı olarak KOİ giderim verimi $\left(\mathrm{KOI}=7826 \mathrm{mg} / \mathrm{L}, \mathrm{pH}=3, \mathrm{Fe}^{2+}=2 \mathrm{~g} / \mathrm{L}, \mathrm{T}=23^{\circ} \mathrm{C}\right.$ ) (COD removal efficincy with respect to $\mathrm{H}_{2} \mathrm{O}_{2} / \mathrm{COD}$ ratio)

\section{4. $\mathrm{Fe}^{2+}$ Dozajinin Etkisi (The Effect of $\mathrm{Fe}^{2+}$ Dosage)}

Fenton prosesinin çalışma verimi ve proses maliyeti açısından Eş. 1'de görüldüğü gibi $\mathrm{Fe}^{2+}$ nin miktarı önemlidir [28]. $\mathrm{Fe}^{2+}$ dozajının KOİ giderim verimine olan etkisini belirlemek amaciyla 0,25 ile $2 \mathrm{~g} / \mathrm{L} \mathrm{Fe}^{2+}$ arasinda değişen konsantrasyonlarda, sabit $\mathrm{H}_{2} \mathrm{O}_{2}, \mathrm{pH}$ ve sicaklıkta Fenton prosesi uygulanmış olup elde edilen sonuçlar Şekil 5'de verilmiştir. 180 dakika süren deneyler sonucunda KOİ giderim verimi (Şekil 5a) $\mathrm{Fe}^{2+}$ dozajına bağlı olarak \%35,690,8 arasında değişmektedir. $\mathrm{Fe}^{2+}$ konsantrasyonunun TOK giderimine olan etkisi ise Şekil 5b'de verilmiştir. 

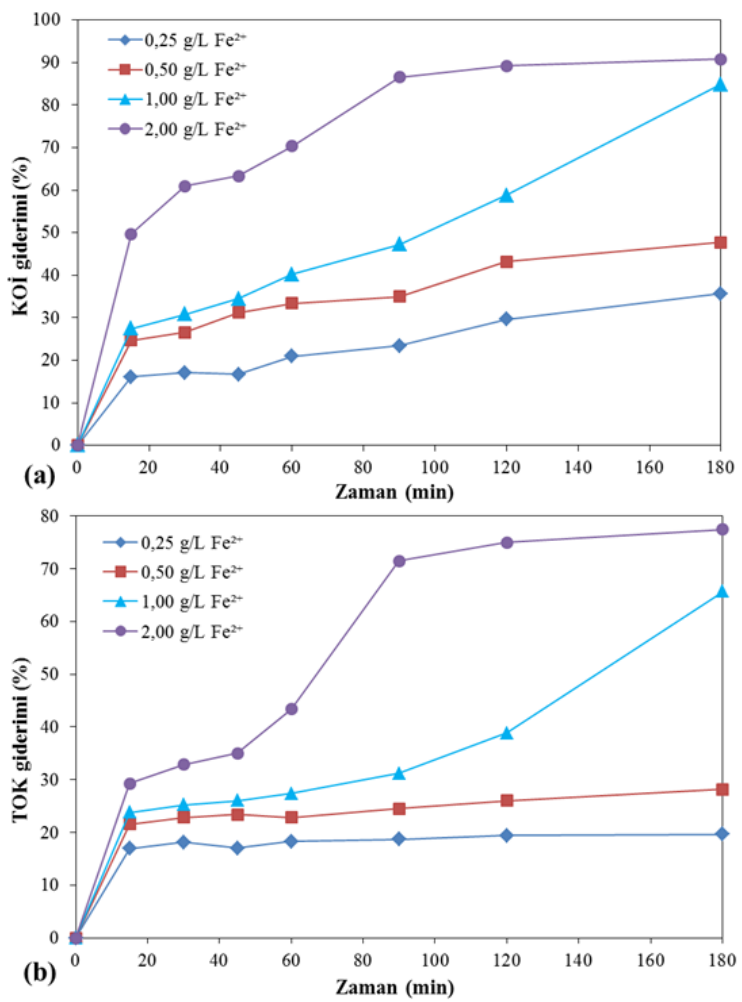

Şekil 5. $\mathrm{Fe}^{2+}$ dozajının KOİ (a) ve TOK (b) giderimine etkisi $\left(\mathrm{T}=23^{\circ} \mathrm{C}, \mathrm{H}_{2} \mathrm{O}_{2}=17,5 \mathrm{~g} / \mathrm{L}, \mathrm{pH}=3, \mathrm{KO} \dot{\mathrm{I}}=7826 \mathrm{mg} / \mathrm{L}\right.$, $\mathrm{TOK}=2041 \mathrm{mg} / \mathrm{L})\left(\right.$ Effect of $\mathrm{Fe}^{2+}$ concentraion on (a) COD (b) TOC removal efficiencies)

$\mathrm{Fe}^{2+}$ konsantrasyonu $0,25 \mathrm{~g} / \mathrm{L}$ 'de TOK giderimi \%19,6 iken $\mathrm{Fe}^{2+}$ konsantrasyonunun $0,5 \mathrm{~g} / \mathrm{L}$ ' de $\% 28,1$ 'e çıkmıştır. Fe ${ }^{2+}$ konsantrasyonu $1 \mathrm{~g} / \mathrm{L}$ olduğunda ise \%65,6'ya ulaşmıştır. En yüksek $\mathrm{Fe}^{2+}$ konsantrasyonunda $(2 \mathrm{~g} / \mathrm{L})$ ise 180 dakika sonunda TOK giderim verimi \%77,4 olarak elde edilmiştir. Farklı $\mathrm{Fe}^{2+}$ dozajlarında reaktör içerisinde kalıntı $\mathrm{H}_{2} \mathrm{O}_{2}$ miktarlarının zamanla değişimi ise Şekil 6' da verilmiştir. $\mathrm{Fe}^{2+}$ konsantrasyonu $0,25,0,5$ ve $1 \mathrm{~g} / \mathrm{L}$ 'de reaktör içerisinde kalınt $\mathrm{H}_{2} \mathrm{O}_{2}$ miktarı 180 dakika sonunda sirasıly $12,7,7$ ve 1,5 g/L'ye kadar düşmüştür. Ancak $\mathrm{Fe}^{2+}$ konsantrasyonu 2 $\mathrm{g} / \mathrm{L}$ 'de kalıntı $\mathrm{H}_{2} \mathrm{O}_{2}$ tespit edilememiştir.

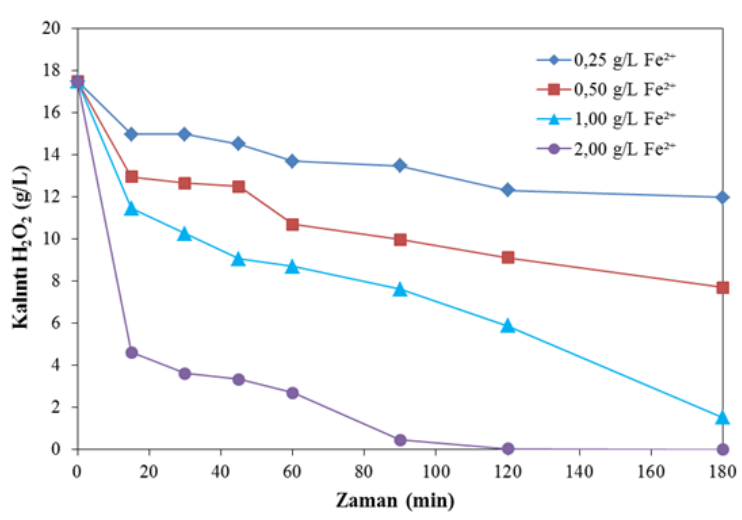

Şekil 6. Farklı $\mathrm{Fe}^{2+}$ dozajlarında kalınt $\mathrm{H}_{2} \mathrm{O}_{2}$ miktarlarının zamanla değişimi $\left(\mathrm{T}=23^{\circ} \mathrm{C}, \mathrm{H}_{2} \mathrm{O}_{2}=17,5 \mathrm{~g} / \mathrm{L}, \mathrm{pH}=3\right.$, $\mathrm{TOK}=2041 \mathrm{mg} / \mathrm{L}, \mathrm{KOI}=7826 \mathrm{mg} / \mathrm{L})($ The variation in residual $\mathrm{H}_{2} \mathrm{O}_{2}$ concentration with respect to time at different $\mathrm{Fe}^{2+}$ concentrations)
$\mathrm{Fe}^{2+}$ konsantrasyonunun artışı ile ${ }^{\circ} \mathrm{OH}$ radikallerinin üretimi ve bunun sonucu olarak da oksidasyon hızı $\operatorname{artar}(\mathrm{R} 1) . \mathrm{Fe}^{2+}$ konsantrasyonunun 1 g/L'den 2 g/L'ye çıkarılması ile KOİ ve TOK giderimlerinde çok fazla artış gözlenmemiştir. Bu nedenle optimum $\mathrm{Fe}^{2+}$ konsantrasyonu $1 \mathrm{~g} / \mathrm{L}$ olarak seçilmiştir. $\mathrm{Bu}$ demir dozajında KOİ ve TOK giderimleri sırasıyla \%84,9 ve \%65,6 olarak belirlenmiştir. Birim KOİ giderimine karşılık tüketilen $\mathrm{H}_{2} \mathrm{O}_{2}$ miktarı hesaplanabilir. $\mathrm{Bu}$ tüketim reaksiyon süresi boyunca değişebilir. Reaksiyon süresi sonunda (180 dakika) 1 gram KOİ giderimi için 2,41 gram $\mathrm{H}_{2} \mathrm{O}_{2}$ tüketilmiştir. $\mathrm{Bu}$ değer teorik olarak ihtiyaç duyulan $\mathrm{H}_{2} \mathrm{O}_{2} / \mathrm{KOI}$ oranının 1.13 katıdır. Optimum demir dozajında (1 g/L) $\mathrm{Fe}^{2+} / \mathrm{H}_{2} \mathrm{O}_{2}$ oranı ağırlıça \%5,7'dir. Fenton oksidasyonu ile atık su arıtımında literatürde $\mathrm{Fe}^{2+} / \mathrm{H}_{2} \mathrm{O}_{2}$ oranı için geniş bir aralık önerilmektedir. $\mathrm{Fe}^{2+} / \mathrm{H}_{2} \mathrm{O}_{2}$ oran1, 2,4-diklorofenol giderimi için \%15 [29], kağıt hamuru atık sularının arıtıldığı bir çalışmada \%0,6 [30], fenol içeren atık suların arıtımında \%50 [31] ve kozmetik atık suyunun arıtımında ise $\% 3,8$ olarak verilmiştir [4].

\subsection{Sicaklı̆̆ın Etkisi (The Effect of Temperature)}

S1caklığın etkisini belirlemek için $\mathrm{pH}, \mathrm{Fe}^{2+}$ ve $\mathrm{H}_{2} \mathrm{O}_{2}$ konsantrasyonları sabit tutularak farklı sicaklıklarda (23$50^{\circ} \mathrm{C}$ ) kimyasal oksijen ihtiyac1 ve toplam organik karbon giderimleri incelenmiştir. Elde edilen sonuçlar Şekil 7'de verilmiştir.
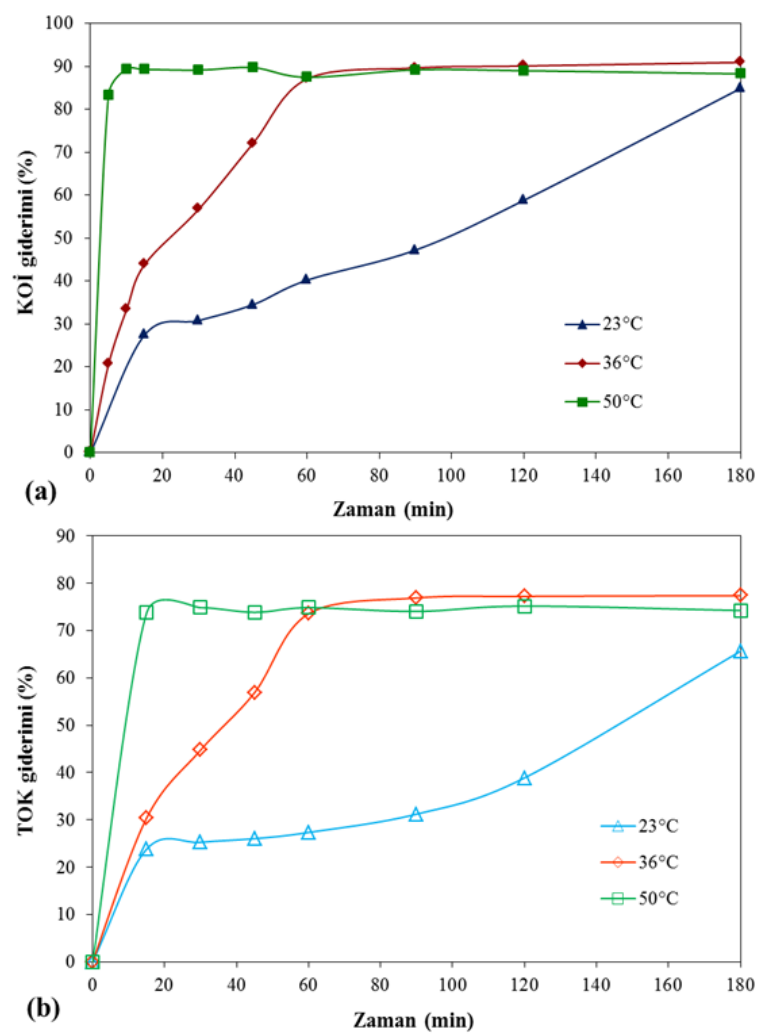

Şekil 7. Farklı sıcaklıkların KOİ (a) ve TOK (b) giderimine etkisi $\left(\mathrm{KOI}=7826 \mathrm{mg} / \mathrm{L}, \mathrm{TOK}=2041 \mathrm{mg} / \mathrm{L}, \mathrm{pH}=3, \mathrm{Fe}^{2+}=1\right.$ $\mathrm{g} / \mathrm{L}, \mathrm{H}_{2} \mathrm{O}_{2}=17,5 \mathrm{~g} / \mathrm{L}$ ) (Effect of different temperatures on (a) COD and (b) TOC removal efficiencies) 
Yapilan denemelerde $23^{\circ} \mathrm{C}$ 'de 180 dakika sonunda KOİ giderimi \%84,9 olarak belirlenmiştir. Sicaklık $36^{\circ} \mathrm{C}$ 'ye yükseltildiğinde ise KOİ giderimi 90'1ncı dakikada \%89,6 iken 180 'inci dakikada $\% 90,9$ olarak bulunmuştur. $36^{\circ} \mathrm{C}$ 'de Fenton prosesi ile giderilebilecek organik maddenin neredeyse tamamı 90'1ncı dakikada giderilmiştir. Sıcaklık $50^{\circ} \mathrm{C}$ 'ye çıkarıldığında ise 5 'inci dakikada KOİ giderimi $\% 83,4$ iken 10'uncu dakikada \%89,4, 180'inci dakika sonunda ise \%88,3'tür. 180 dakika sonunda KOİ gideriminde ki düşüşün sebebi olarak yüksek sıcaklıkta meydana gelen buharlaşmadan kaynaklandığ düşünülmektedir (Şekil 7a). TOK değerleri 23, 36 ve $50^{\circ} \mathrm{C}$ 'de sirasiyla 702,462 ve $526 \mathrm{mg} / \mathrm{L}$ olarak bulunmuştur. $50^{\circ} \mathrm{C}$ 'de 15 dakikada $36^{\circ} \mathrm{C}$ 'de ise 60 dakikada TOK giderimleri kararlı hale ulaşmıştır. Ancak $23^{\circ} \mathrm{C}^{\prime} \mathrm{de}$ 180 dakikadan sonra reaksiyonun devam ettiği söylenebilir (Şekil 7b). Tablo 1'de belirtilen İSKİ kanalizasyona deşarj limitlerini sağlamak amacıyla kozmetik atık suyunun arıtımında $36^{\circ} \mathrm{C}$ 'de optimum reaksiyon süresi, $\mathrm{pH}, \mathrm{Fe}^{+2}$ ve $\mathrm{H}_{2} \mathrm{O}_{2}$ konsantrasyonları sırasıyla 90 dakika, $\mathrm{pH} 3,1 \mathrm{~g} / \mathrm{L}$ ve $17,5 \mathrm{~g} / \mathrm{L}$ olarak belirlenmiştir. KOİ çıkış konsantrasyonu ise $811 \mathrm{mg} / \mathrm{L}$ olup deşarj limitleri sağlanmıştır.

Kalıntı $\mathrm{H}_{2} \mathrm{O}_{2}$ konsatrasyonlarının değişimi ise Şekil 8'de verilmiş olup $50^{\circ} \mathrm{C}$ 'de 5 dakikada $36^{\circ} \mathrm{C}$ 'de ise 60 dakikada ilave edilen $\mathrm{H}_{2} \mathrm{O}_{2}$ 'in \%95'i tükenmektedir. Ancak $23^{\circ} \mathrm{C}$ 'de 180 dakika sonunda $1,5 \mathrm{~g} / \mathrm{L} \mathrm{H}_{2} \mathrm{O}_{2}$ kalmakta olup tüketilen miktar ilave edilen $\mathrm{H}_{2} \mathrm{O}_{2}$ 'nin \%91,4'üne karş1lık gelmektedir.

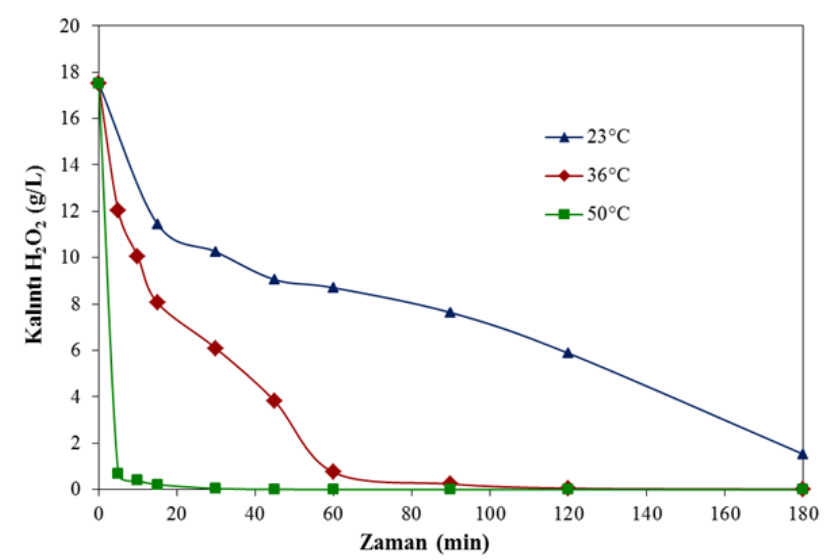

Şekil 8. Farklı sıcaklıklarda kalıntı $\mathrm{H}_{2} \mathrm{O}_{2}$ konsatrasyonlarının değişimi $(\mathrm{KOI}=7826 \mathrm{mg} / \mathrm{L}, \mathrm{pH}=3$, $\mathrm{Fe}^{2+}=1 \mathrm{~g} / \mathrm{L}, \mathrm{H}_{2} \mathrm{O}_{2}=17,5 \mathrm{~g} / \mathrm{L}$ ) (The variation in residual $\mathrm{H}_{2} \mathrm{O}_{2}$ concentration with respect to time at diffrent temperatures)

\subsection{Sicaklı̆̆a Bă̆lı Olarak KOİ Giderim Kinetiği}

(Kinetics of COD Removal Depending on the Temperature)

Endüstriyel atık suların karmaşık doğası nedeniyle Fenton oksidasyonu ile bir kinetik analiz çıkarmak kolay değildir. Ancak bu durumda, KOİ gibi organik maddeyi temsil eden bir parametreye göre kinetik çalışma yapmak mümkündür [27]. Bu amaçla farklı sıcaklıklar için 180 dakika boyunca KOİ değişimleri verilen atık suyun birinci derece (Eş. 1), yalancı birinci derece (Eş. 2) ve ikinci derece (Eş. 3) reaksiyon kinetikleri $[32,33]$ incelenmiştir.

$$
\begin{aligned}
& \ln C=\ln C_{o}-k_{1} t \\
& \ln \left(C-C_{e}\right)=\ln \left(C_{o}-C_{e}\right)-k_{1}, t \\
& \frac{1}{C}=\frac{1}{C_{o}}+k_{2} t
\end{aligned}
$$

Bu eşitliklerde $C_{0}$ başlangıç KOİ konsantrasyonu (mg/L); $C$ herhangi bir zamandaki KOİ konsantrasyonu $(\mathrm{mg} / \mathrm{L}) ; C_{e}$ denge konsantrasyonu olup oksitlenemeyen KOİ konsantrasyonu $(\mathrm{mg} / \mathrm{L}) ; k_{1}, k_{1}$, ve $k_{2}$ sirasiyla 1.derece, yalanc1 1.derece ve 2.derece reaksiyon kinetiğine ait kinetik sabitleri; ve $t$ reaksiyon süresini (dakika) ifade etmektedir.

Eş. 2'de belirtilen denge konsantrasyonu değeri oksitlenemeyen KOİ değeri olup tüm sıcaklıklar için eşit alınmıştır. $23^{\circ} \mathrm{C}$ 'de reaksiyon tamamlanmamış olsa dahi diğer sonuçlar göz önüne alındığında (farklı $\mathrm{Fe}^{2+}$ dozajı, $\mathrm{H}_{2} \mathrm{O}_{2}$ dozaj1 ve sicaklıklar için) 180 dakika sonunda oksitlenmeyen kısım aynı olacaktır. Bu nedenle Ce değeri olarak en düşük KOİ değeri olan ve Şekil 1'de belirtilen 240 dakika sonunda elde edilen KOİ değeri $(704 \mathrm{mg} / \mathrm{L})$ alınmıştır. Kinetik parametreler hesaplanırken kinetik eşitliğin derecesine göre lineer hale getirilen grafiklerin eğimleri kullanılmıştır. Farklı sıcaklıklarda yapılan denemelerden elde edilen veriler kullanılarak (Şekil 7-a) her bir reaksiyon kinetiği için hesaplanan kinetik parametreler Tablo 2'de verilmiştir.

Kinetik parametreler incelendiğinde birinci derece, yalanc1 birinci derece ve ikinci derece kinetik için ortalama $\mathrm{R}^{2}$ değerleri sirasiyla $0,9278,0,9622$ ve 0,9574 olarak hesaplanmıştır. Tüm sıcaklıklarda yalancı birinci derece kinetiğe ait ortalama $\mathrm{R}^{2}$ değeri diğerlerinden daha yüksektir. Bu değerler göz önüne alındığında kozmetik atık

Tablo 2. Fenton oksidasyonu ile KOİ giderimi için hesaplanan kinetik sabitler (The kinetic constants calculated for COD removal by Fenton oxidation)

\begin{tabular}{lllllll}
\hline Sicaklı $\left({ }^{\circ} \mathrm{K}\right)$ & \multicolumn{2}{c}{ 1.derece kinetik } & \multicolumn{2}{c}{ Yalanc1 1. derece kinetik } & \multicolumn{2}{c}{ 2.derece kinetik (*1000) } \\
& $\mathrm{k}_{1}(1 / \mathrm{min})$ & $\mathrm{R}^{2}$ & $\mathrm{k}_{1},(1 / \mathrm{min})$ & $\mathrm{R}^{2}$ & $\mathrm{k}_{2}(\mathrm{~L} / \mathrm{mg} \cdot \mathrm{min})$ & $\mathrm{R}^{2}$ \\
\hline 296 & 0,0063 & 0,9299 & 0,0074 & 0,9372 & 0,0013 & 0,9543 \\
309 & 0,0262 & 0,9603 & 0,0472 & 0,9665 & 0,0129 & 0,9298 \\
323 & 0,2244 & 0,8931 & 0,4035 & 0,9828 & 0,1077 & 0,9881 \\
\hline
\end{tabular}


suyunun Fenton oksidasyonu ile gideriminde yalancı birinci derece reaksiyon kinetiğine uyduğu söylenebilir. Şekil 9'da farklı sıcaklıklar için lineer hale getirilmiş yalancı birinci derece kinetik gösterilmektedir.

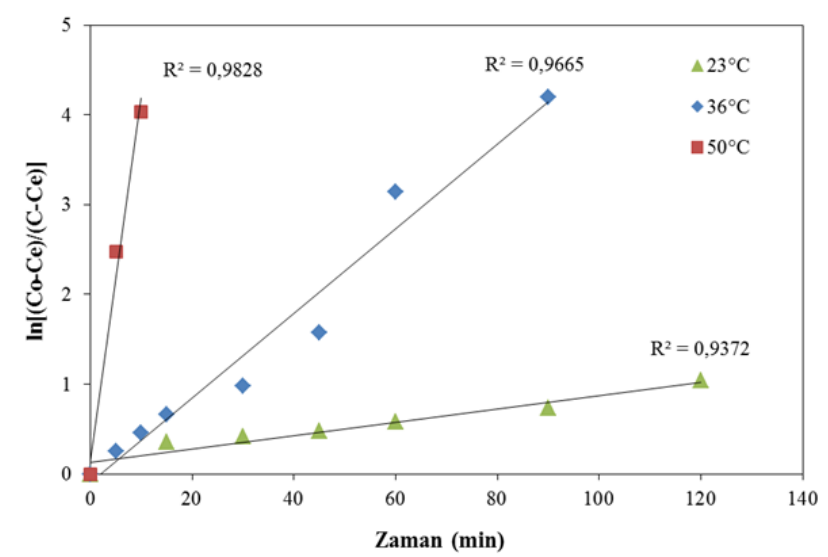

Şekil 9. Farklı sıcaklıklarda lineer hale getirilmiş yalancı birinci derece kinetik

(Linearized pseudo-first order kinetic graphs obtained at different temperatures)

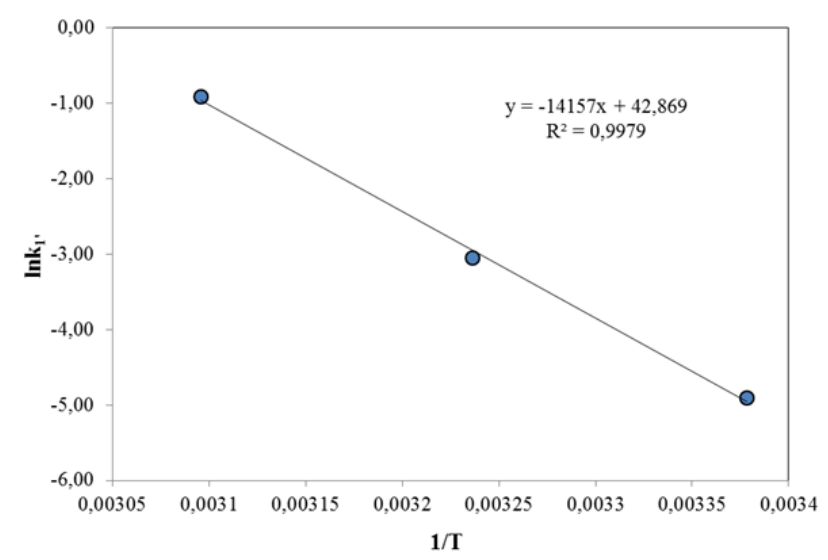

Şekil 10. Gözlenen yalancı birinci dereceden kinetik sabitler için Arrhenius grafiği

(Arrhenius graph for observed pseudo-first order kinetic constants)

Arrhenius denklemi (Eş. 4) reaksiyon sıcaklığı ve spesifik reaksiyon hızı $(k)$ arasındaki ilişkiyi gösterir.

$$
\ln k_{1^{\prime}}=\ln A_{o}-\frac{E_{a}}{R T}
$$

Arrhenius denkleminde $1 / T^{\prime}$ ye karşı $\ln k$ grafiği çizilirse (Şekil 10) $E_{a}$ (aktivasyon enerjisi) ve $A_{0}$ (ön üstel faktör/frekans faktörü/moleküllerin birbirine çarpma hızı) parametreleri hesaplanabilir. $\mathrm{Bu}$ denklemde $R$ ideal gaz sabiti $\left(8,314 \mathrm{~J} / \mathrm{mol}^{\circ} \mathrm{K}\right)$ ve $T$ mutlak sicaklığ $\left({ }^{\circ} \mathrm{K}\right)$ göstermektedir. Aktivasyon enerjisi bir reaksiyonun başlayabilmesi için bileşenlerin sahip olmaları gereken en düşük enerji olarak tanımlanır. Sıradan bir termal reaksiyonun aktivasyon enerjisi $60-250 \mathrm{~kJ} / \mathrm{mol}$ arasındadır [34]. Şekil 10 yardımıyla aktivasyon enerjisi $\left(E_{a}\right)$ 117,7 $\mathrm{kJ} / \mathrm{mol}, A_{0}$ ise $4.15 \times 10^{18}$ dakika $^{-1}$ olarak hesaplanmıştır.

\section{SONUÇLAR (CONCLUSIONS)}

$\mathrm{Bu}$ çalışma sonucunda kozmetik atık suyunun giderimi için Fenton prosesinin uygun bir yöntem olduğu söylenebilir. Kozmetik üretimi atık sularından KOİ ve TOK giderimine ait uygulamada yararlanılabilecek önemli sonuçlar elde edilmiştir. Fenton prosesinde optimum değerler başlangıç $\mathrm{H}_{2} \mathrm{O}_{2}=17,5 \mathrm{~g} / \mathrm{L}, \mathrm{Fe}^{2+}=1 \mathrm{~g} / \mathrm{L}, \mathrm{pH}=3, \mathrm{~T}=36^{\circ} \mathrm{C}$, reaksiyon süresi 90 dakika için KOİ ve TOK giderimi sırasıyla \%89,6 ve $\% 76,9$ olarak bulunmuştur. KOİ çıkış konsantrasyonu $811 \mathrm{mg} / \mathrm{L}$ olup deşarj limitleri sağlanmıştır. KOİ'ye dayalı bir kinetik analiz gerçekleştirilmiş ve KOİ gideriminin yalancı birinci derece kinetiğe uyduğu belirlenmiş olup Arrhenius eşitliğinde aktivasyon enerjisi 117,7 kJ/mol olarak hesaplanmıştır. İşletme maliyeti düşünüldügünde daha düşük sicaklık, $\mathrm{Fe}^{+2}, \mathrm{H}_{2} \mathrm{O}_{2}$ konsantrasyonlarında ve daha uzun reaksiyon süresinde yüksek organik madde içeriği azaltılabilir.

Ayrıca Fenton prosesi yüksek organik madde içeren atık suların arıtımında biyolojik arıtma ünitelerine ön arıtma prosesi olarak entegre edilerek biyolojik arıtım prosesinin giderim verimlerine katkı sağlayabileceği düşünülmektedir.

\section{TEŞEKKÜR (ACKNOWLEDGEMENT)}

$\mathrm{Bu}$ çalışma Atatürk Üniversitesi, Bilimsel Araştırma Projeleri (BAP) birimi tarafından 2012/97 nolu proje kapsamında desteklenmiştir.

\section{KAYNAKLAR (REFERENCES)}

1. Bogacki J., Naumczyk J., Marcinowski P., Kucharska M., Treatment of cosmetic wastewater using physicochemical and chemical methods, Chemik, 65, 94-97, 2011.

2. Naumczyk J., Bogacki J., Marcinowski P., Kowalik P., Cosmetic wastewater treatment by coagulation and advanced oxidation processes, Environ. Technol., 35 (5), 541-548, 2014.

3. Puyol D., Monsalvo V.M., Mohedano A.F., Sanz J.L., Rodriguez J.J., Cosmetic wastewater treatment by upflow anaerobic sludge blanket reactor, J. Hazard. Mater., 185 (2-3), 1059-1065, 2011.

4. Bautista P., Mohedano A.F., Gilarranz M.A., Casas J.A., Rodriguez J.J., Application of Fenton oxidation to cosmetic wastewaters treatment, J. Hazard. Mater., 143 (1-2), 128-1, 2007.

5. Boroski M., Rodrigues A.C., Garcia J.C., Sampaio L.C., Nozaki J., Hioka N., Combined electrocoagulation and $\mathrm{TiO} 2$ photoassisted treatment applied to wastewater effluents from pharmaceutical and cosmetic industries, J. Hazard. Mater., 162 (1), 448-454, 2009.

6. Bautista P., Mohedano A.F., Menendez N., Casas J.A., Rodriguez J.J., Catalytic wet peroxide oxidation of cosmetic wastewaters with Fe-bearing catalysts, Catal. Today, 151 (1-2), 148-152, 2010. 
7. Huisman I., Optimising UF for wastewater treatment through membrane autopsy and failure analysis, Filtr. Sep., 41 (3), 26-27, 2004.

8. Monsalvo V.M., Lopez J., Somer M.M., Mohedano A.F., Rodriguez J.J., Short-term fouling control by cyclic aeration in membrane bioreactors for cosmetic wastewater treatment, Desalin. Water Treat., 56 (13), 3599-3606, 2015.

9. Tobajas M., Polo A.M., Monsalvo V.M., Mohedano A.F., Rodriguez J.J., Analysis of the operating conditions in the treatment of cosmetic wastewater by sequencing batch reactors, Environ. Eng. Manage. J., 13 (12), 2955-2962, 2014.

10. Primo O., Rivero M.J., Ortiz I., Photo-Fenton process as an efficient alternative to the treatment of landfill leachates J. Hazard. Mater., 153 (1-2), 834-842, 2008.

11. Neyens E., Baeyens J., A review of classic Fenton's peroxidation as an advanced oxidation technique, $\mathrm{J}$. Hazard. Mater., 98 (1-3), 33-50, 2003.

12. Haber F., Weiss J., The Catalytic Decomposition of Hydrogen Peroxide by Iron Salts, Proc. R. Soc. London, Ser. A, 147 (861), 332-351, 1934.

13. Walling C., Fenton's reagent revisited, Acc. Chem. Res., 8 (4), 125-131, 1975.

14. Fenton H.J.H., LXXIII.-Oxidation of tartaric acid in presence of iron, J. chem. Soc. Trans., 65, 899-910, 1894.

15. Kang Y.W., Hwang K.Y., Effects of reaction conditions on the oxidation efficiency in the Fenton process, Water Res., 34 (10), 2786-2790, 2000.

16. Fan C., Horng C.-Y., Li S.-J. Structural characterization of natural organic matter and its impact on methomyl removal efficiency in Fenton process, Chemosphere, 93 (1), 178-183, 2013.

17. Zhang J., Chen S., Zhang Y., Quan X., Zhao H., Zhang $Y$., Reduction of acute toxicity and genotoxicity of dye effluent using Fenton-coagulation process, J. Hazard. Mater., 274, 198-204, 2014.

18. Lopez A., Pagano M., Volpe A., Di Pinto A.C., Fenton's pre-treatment of mature landfill leachate, Chemosphere, 54 (7), 1005-1010, 2004.

19. Santana C.S., Aguiar A., Effect of biological mediator, 3-hydroxyanthranilic acid, in dye decolorization by Fenton processes, Int. Biodeterior. Biodegrad., 104, 17, 2015 .

20. İSKİ Genel Müdürlüğü Atıksuların Kanalizasyona Deşarj Yönetmeliği, 2013, http://www.iski.gov.tr/web/assets/SayfalarDocs/Mevzu at $\% 20 \mathrm{ve} \% 20 \mathrm{Y} \% \mathrm{C} 3 \%$ B6netmelikler/ISKI_Atiksularin Kanalizasyona_Desarj_Yonetmeligi.pdf, Erişim Tarihi Ocak 18, 2017.
21. Klassen N.V., Marchington D., McGowan H.C.E., $\mathrm{H} 2 \mathrm{O} 2$ Determination by the $\mathrm{I}^{-}$Method and by KMnO4 Titration, Anal. Chem., 66 (18), 2921-2925, 1994.

22. Clesceri L.S., Eaton A.D., ve Greenberg A.E., Standard Methods for the Examination of Water and Wastewater, American Public Health Association, California, 1998.

23. Talinli I., Anderson G.K., Interference of hydrogen peroxide on the standard COD test, Water Res., 26 (1), 107-110, 1992.

24. Elmolla E.S., Chaudhuri M., The feasibility of using combined Fenton-SBR for antibiotic wastewater treatment, Desalination, 285, 14-21, 2012.

25. Lin S.H., Lo C.C., Fenton process for treatment of desizing wastewater, Water Res., 31 (8), 2050-2056, 1997.

26. Singh S.K., Tang W.Z., Statistical analysis of optimum Fenton oxidation conditions for landfill leachate treatment, Waste Manage. (Oxford), 33 (1), 81-88, 2013.

27. Lucas M.S., Peres J.A., Removal of COD from olive mill wastewater by Fenton's reagent: Kinetic study, J. Hazard. Mater., 168 (2-3), 1253-1259, 2009.

28. Özdemir C., Öden M.K., Şahinkaya S., Güçlü D., The sonochemical decolorisation of textile azo dye CI Reactive Orange 127, Color. Technol., 127 (4), 268273, 2011.

29. Tang W.Z., Huang C.P., 2,4-Dichlorophenol Oxidation Kinetics by Fenton's Reagent, Environ. Technol., 17 (12), 1371-1378, 1996.

30. Pérez M., Torrades F., Domènech X., Peral J., Removal of organic contaminants in paper pulp effluents by AOPs: an economic study, Jo J. Chem. Technol. Biotechnol., 77 (5), 525-532, 2002.

31. Eisenhauer H.R., Oxidation of phenolic wastes, J. Water Pollut. Control Fed., 36 (9), 1116-1128, 1964.

32. Basturk E., Karatas M., Advanced oxidation of Reactive Blue 181 solution: A comprasion between Fenton and Sono-Fenton Process, Ultrason. Sonochem., 21 (5), 1881-1885, 2014.

33. Okur M., Akt1 F., The removal of C.I. acid violet 90 metal-complex dye using synthetic and natural zeolite from aqueous solutions, Journal of the Faculty of Engineering and Architecture of Gazi University, 31 (3), 677-686, 2016.

34. Kasiri M.B., Aleboyeh H., Aleboyeh A., Mineralization of C.I. Acid Red 14 azo dye by $\mathrm{UV} / \mathrm{Fe}$ ZSM5/H2O2 process, Environ. Technol., 31 (2), 165-173, 2010. 